\title{
Strategic management practices in organisations with specific reference to the public sector
}

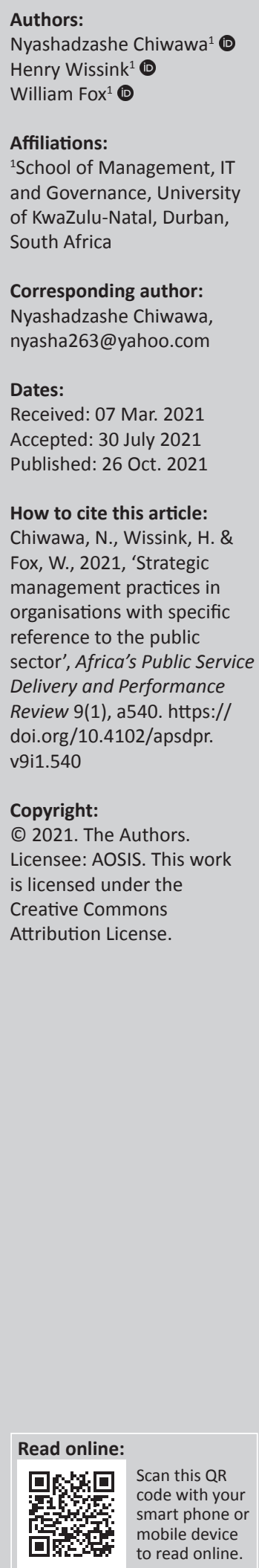

Background: The traditional models for strategic management are approaching limits in the light of increasing uncertainty to define what public service organisations must be able to achieve in terms of efficiency and satisfaction of stakeholder expectations. However, the dynamism of economic patterns calls for versatility that is deliberately designed.

Aim: This article aimed to explore the importance of conflating the dimensions of strategic management triangle, in conjunction with the limits of traditional models, towards effective and sustainable public sector management.

Setting: The chosen government ministry is headquartered in Harare, Zimbabwe. The ministry comprises nine departments, each headed by an appointed director who acts as the Head of Department (HOD).

Methods: A qualitative research approach was employed and a sample of eight participants, consisting of HODs, was purposefully selected from the population. Open-ended qualitative responses were analysed thematically.

Results: The results suggest that effective and sustainable public sector strategic management requires not only a single invariant approach but a set of values, processes, procedures, tools, techniques and practices that must be selectively and strategically adapted to unique situations in order to produce desirable results.

Conclusion: A strategic triangle admixture of 'legitimacy and support', 'operational capabilities' and 'public value' offers more marginal flexibility, decreases uncertainty, generates more focus, and is easily understandable when pursuing effective public sector management. However, this approach needs to be considered in conjunction with the traditional models to optimise set goals.

Keywords: strategic management; management practices; public sector; policy development; strategic triangle; logical incrementalism.

\section{Introduction}

Strategic management was adopted as an important management tool in the business and public sectors with its emergence in military affairs, and in reaction to an uncertain, turbulent and chaotic environment. Strategic management makes it possible to define the vectors of the organisation's future growth with a specific setting of the activity's strategic and tactical objectives (Van Dooren, Bouckaert \& Halligan 2015). Strategy links the organisation to the external setting and is reflected in management's pattern of movements and techniques designed to achieve the desired results. The development of a strategy is a managerial commitment to follow a clear set of actions to develop the business, attract and satisfy clients, compete effectively, execute operations, and enhance the financial and market performance of the organisation (Talbot 2010). Therefore, the strategy of an organisation is all about how management plans to grow the business, how it will create loyal customers, how it will outcompete rivals, how to run each organisational functional part, and how to improve efficiency.

Throughout the literature, the strategic management concept comes with contradictory definitions. A cursory observation, however, shows a significant consensus on the key activities involving 'doing'.

Pemberton and Stonehouse (2004) conceptualised strategic management as a set of ideas and structures from which executives can visualise and prepare the organisation as a whole for the long-term future. 
Strategic management can therefore be described as the art and science of formulating, implementing and evaluating cross-functional decisions that allow an organisation to achieve its goals. Poister (2010) defined strategic management as the ongoing process of formulating, implementing and controlling broad plans that guide the organisation, given its internal and external environment, to achieve strategic objectives. Top management should take into account the resources available and, in addition, carry out an overview of the micro and macro environment in which the organisation is competing. Strategies are crucial for businesses because they guide top management to set directions, concentrate resources and consistently guide necessary environmental responses (Bryson \& Edwards 2017).

The 'strategic management' description depicts it as a deliberate part of a different set of activities to provide a unique set of values as a means of gaining competitive advantage. However, the process is affected by both internal and external variables. Therefore, strategic management procedurally increases as a social accomplishment activity for achieving certain strategic objectives and focused on the activities and engagement of various stakeholders within and outside the organisation (Hendry et al. 2010). The numerous methods that an organisation undertakes to achieve its goals are strategic management practices. The organisation must ensure that it focuses on its areas of strength so that it does not disappoint in service delivery.

The complexities of an uncertain internal organisational environment have expanded dramatically. Furthermore, the rate of change in the corporate environment has accelerated in recent years, resulting in increased uncertainties (Altland \& Simons 2010). The goal of strategic planning is to improve an organisation's efficiency and effectiveness by strengthening current and future operations. Strategic planning provides a lens through which management can see the future. Strategic planning methods describe how an organisation might change in order to take advantage of new opportunities that could help it meet stakeholder's needs. This procedure is typically used by management to develop objectives, set targets and provide timelines for completing certain activities, as well as mechanisms for tracking progress. The technique could be used to provide a means for assigning responsibilities in terms of who will complete the work in operational planning.

\section{Theories impacting public sector strategic management}

The idea of what the state can do for a society and what not is a process of continuous deliberation, debate and negotiation, and is carried out by politicians who then develop policies through the democratic process (Maas \& Svorenčík 2017). This deliberation process is also influenced by other interest groups, such as citizens' action groups, beneficiaries and other administrative bodies. Policy interpretation then works to develop services for public entities and serve the public in addressing social challenges (Briones 2020). Strategic management can be thought of as a combination of strategy formulation, implementation and evaluation because it is the process and approach of specifying an organisation's objectives, developing policies and plans to achieve and attain these objectives and allocating resources to implement the policies and the plans (Briones \& Bollo 2017).

According to Immers and Duijn (2005), there is currently a contrasting style of governance in the public sector between the hierarchical approach and the consensus approach, with the consensus approach being increasingly used to promote the execution of public policy because of time and space constraints.

However, hierarchical governance structures have been around for a long time and have had dominance in the public sector in terms of how it conducts business, determining the timeliness, relevance and effectiveness of public policy implementation, as well as the benefits gained by the citizenry (Engida \& Bardill 2013). A top-down approach to problem solving is the main feature reflected in hierarchical government structures, whereby the bottom layers of the bureaucracy await orders from the top layers and the results of the implementation of the directives then filter back from the bottom layers to the top. Consequently, in any hierarchical structure, even though the mechanism is well documented and roles are well specified, the essence of the policy directives and timeliness can be lost, resulting in inefficiencies and ineffectiveness.

The 'new public management' (NPM) has been adopted by many governments as a government modernising framework and public sector reengineering. Indeed, the NPM provides essential lessons and analyses for public administration around the world, and African countries are no exception when it comes to putting efforts in place to achieve the goals outlined in the NPM (Pollitt \& Bouckaert 2017).

This necessitates an exploration of the contextual relationships between the various public management models as applied to public sector reform in Africa, as well as the consequences emanating thereto. Moore (1995) coined the term 'public value management' as an alternative to the NPM, which dominated public policy at the time and was characterised by targets, individual priorities and market mechanisms. The public value definition, on the other hand, is centred on the needs of the public as people and consumers, on the building of value rather than meeting targets and on public value being more than the accumulation of individual needs, with deliberation as to what constitutes public value at its core.

The traditional public management (TPM) is dedicated to removing the corrupting power of economic and political interests. The NPM focuses on efficiency models focused on market forces (Hope 2005). Public value theory (PVT) considers all of these issues within a wider sense of democratic politics and public life, whilst TPM lacks a focused concern on economic efficiency and NPM lacks a focused concern on corruption. Public value theory, unlike TPM and NPM, is a process-based model of public administration. The inefficiencies of bureaucratic administration systems and 
traditional hierarchical modes of governance prompted the development of network governance (NG). As a result of the cross-agency approach required to address the imbricating responsibilities of various government agencies and the acceptance of a systemic and holistic approach to government, networks are being used in the public sector in policy development, problem solving and goods and service delivery. Emerson and Nabatchi (2015:9) defined NG as:

$[T]$ he processes and structures of public policy decision making and management that engage people constructively across the boundaries of public agencies, levels of government, and/or the public, private and civic spheres in order to carry out a public purpose that could not otherwise be accomplished.

Previously, administration was just the application method to administer legislation (Da Silva et al. 2019). However, public administration has become more complicated because of the rising complexities of social issues, the increasing demands by people for administration to be viewed as partners and consumers with the right to more quality and quantity and the acceleration of social change. Public administration has increasingly become as a partner of politicians in the concept of what value should be generated and the approach towards attaining the identified value. Policy interpretation and logical translation into management remain iterative and contradictory, often leading to compromises (Thom \& Ritz 2008). Moore's (1995) strategic triangle (see Figure 1) is a management model that allows public officials to make calculated decisions based on the political context whilst pursuing policy objectives. Accordingly, this article opts to explore the importance of strategic management practices in Zimbabwean public sector through the optical lens of a 'strategic triangle' as a directing and coordination method for management and workers.

\section{The strategic management triangle}

At the top of the three main dimensions of strategic management triangle is 'legitimacy and support', which represents political management, mainly seeking political support element for public sector management (managing up).

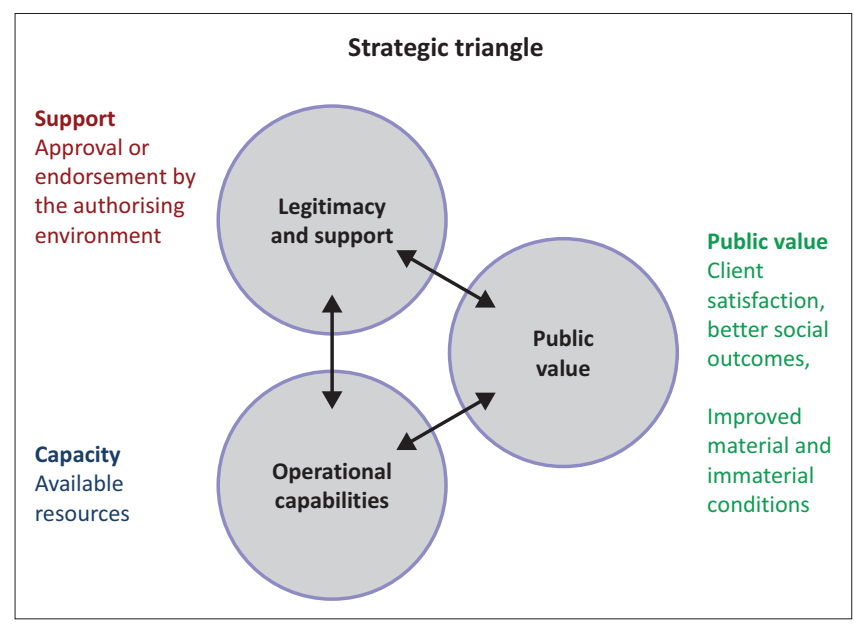

Source: Moore, M.H., 1995, Creating public value: Strategic management in government Harvard University Press, Cambridge

FIGURE 1: The strategic triangle.
The key persons here are the heads of department responsible for all three dimensions of the triangle. Next is the 'operational capabilities', a dimension basically catering for operations management (managing down) for maximising the efficiency and effectiveness of public sector management. The key players here are the staff responsible for operations of public sector business. The third dimension is 'public value', which is fundamentally 'cooperation management' (managing outward) for collaboration, co-production and networking between social actors. Key persons for this assignment are the middle management responsible for cooperation and operations management. The goal is to achieve public value through better social outcomes to the satisfaction of targeted beneficiaries, by improved material and service conditions.

McBain and Smith (2010) proposed that the public manager must manage the ends of the triangle for implementing the strategy and creating value for the society. These management dimensions are often regarded as being essential and intuitive in the management of public sector strategy, to the point that even a novice to the model could apply it. These observations can be made in the social reality of strategy implementation, observing the relevance of the triangle and factors that influence the dimensions during execution, and therefore responding to the outcomes in an appropriate manner.

\section{Conceptualising strategy and strategic management Strategy}

An organisation's strategy is the processes and procedures followed in using resources towards implementing certain policies to achieve the institution's key objectives (Kenis \& Provan 2009). It is essential for government institutions to examine the premise that, according to them, suggests that public organisations need an appropriate methodology to ensure the organisation's objectives, regardless of changes. According to Weick and Sutcliffe (2015), the following four things should be identified by each organisation in formulating its strategy: (1) the mission/ultimate organisational aim, (2) the organisational transformation technologies used, (3) strategic operational plans to achieve the goals and (4) strategic control.

Organisations should plan beyond vision. The concern for action led to the dropping of the word strategic planning and instead using the phrase strategic management. A 'strategy' is often known as the 'game plan' of the company, and executives frequently refer to it as their large-scale, future-oriented, plan to engage with the competitive environment to accomplish the goals of the organisation (Raab, Mannak \& Cambré 2015). A well-defined strategic plan offers a framework for how to accomplish a winning goal. Similarly, it offers a basis for management decisions, but does not detail all possible resource deployments, such as financing, people and materials. A strategy thus represents the understanding of an entity of how, when, where and who it should compete against and the reasons it should compete (Bryson \& Edwards 2017). 
In order for the public sector manager to explain the 'strategy' and 'strategic' concepts, decisions and acts that are 'strategic' and those that are 'tactical' need to be differentiated. Public service managers make various decisions daily. Those decisions that respond to routine issues are referred to as tactical, whilst those decisions with the potential to have a far more fundamental effect on the well-being or direction of the organisation are strategic (Bryson \& Schively Slotterback 2017). Strategic decisions not only form and characterise an organisation but also have the ability to impact an organisation's bottom-line financial health and/or industry, and even the organisation's existence. As a consequence, strategic management is a practice that is of fundamental significance. Strategic decision-making requires large resource reallocations. Strategic decisions can potentially shift an organisation's mission and course, and thus lead to significant changes in the organisation's meaning, size and scope. More than one functioning department seems to be involved. Strategic decision-making typically cuts through various functions and departments (Kania \& Kramer 2011).

\section{Strategic management}

Strategic management is the organisation's art and science in formulating, implementing and reviewing cross-functional decisions that will enable the achievement of set objectives (David 2013). It is a strategic plan that is centred on the complexities of the total environment of the business. Thus, strategic management can be defined by the following three categories:

- There must be a plan, a clear path of the organisation and a means of getting there, which involves the development of a strong competitive position

- Itwillbeimportant toenforceexcellencein operationalising those strategies in order to establish successful output within the organisation

- Innovation needs to be promoted amongst members in order to ensure that the company can adapt to demands for reform and strengthened and refreshed strategies.

Ahmadi et al. (2012) agreed with the given concept, but point out that strategic leadership often requires management decisions and actions that decide the organisation's long-term success. This includes formulation, execution, assessment and control of strategy. They further postulate that strategic management, in view of the strengths and vulnerabilities of the organisation, also stresses the monitoring and assessment of environmental constraints and opportunities. The strategic management process is therefore an organisational analysis process where the current situation and potential course and or manner of the profile and external environment of the organisation are analysed in order to set targets, formulate strategies that achieve the goals, as well as track and analyse the success of the organisation and the outcomes that the strategies yield (Poister, Edwards \& Pasha 2013).

\section{Strategic management process}

Strategic management aims to effectively connect an organisation to its surroundings. Political, social, technological and economic factors all play an integral role in the organisational environment (George et al. 2018). Strategic management, like strategic planning, is made up of a collection of generic approaches that must be tailored to individual settings (Ferlie \& Ongaro 2015). The goal of strategic management techniques is to develop a framework for managing a public institution. Each strategic management approach contains a set of arrangements that drive specific actors, increase the likelihood of specific issues and favour specific strategies. The strategic management approach comprises formulating a strategy, putting that strategy into action, and ultimately monitoring and evaluating that strategy. The phase of planning strategy and environmental analysis is also critical and most authors include it in the formulation phase (Emerson \& Nabatchi 2015).

There is a difference between public sector and private sector styles of management. The public sector is responsible for delivering public policy and performing activities such as fiscus (Maleka 2014). It is mostly immune to the forces of competition, although competition does exist within the organisation, such as between departments competing for limited government funds. In the public sector, strategy is usually focused on meeting objectives to satisfy the political process whilst also demonstrating efficiency and value for money to reassure taxpayers. Political pressure frequently leads to shifts in objectives in order to win voter support, as well as a short-term perspective that has an impact on longterm strategic planning. Private sector, on the other hand, is mainly characterised by competition and profit making (Joyce 2015). Companies can only survive if they produce better products or services than their competitors, therefore the concept of long-term competitive advantage is frequently at the centre of business strategy. Time is another important aspect of private sector strategy. Because the time it takes to develop new products and bring them to market is often short, there can be a conflict between achieving short-term profitability and planning and resourcing a long-term strategy (Sandfort \& Moulton 2015).

\section{Research design and methodology}

The methodology of the study comprises the research design, population of the study, sampling procedures, and data collection and analysis procedures (Daymon \& Holloway 2010). Data for the study comprised two main sources namely secondary and primary sources. The qualitative strategy, because of its naturality and inductiveness to originality, was chosen. A case study design was used because it was considered appropriate in a limited context to explore the significance of strategic management practices in the public sector (Biedenbach \& Müller 2011). In this study, the qualitative approach is important because the authors wanted to understand how participants interpret public sector strategic management practices (Nieuwenhuis 2016). Their insights have helped to make sense of how strategic management practices in public service operate. The Ministry of finance and economic development, with head office in Harare, Zimbabwe, was the study site. 
A sample of eight participants, consisting of department heads (HODs), was purposefully selected from the population. To ensure trustworthiness, participants were given a chance to comment on the transcribed results, as the authors used member check. For dependability, the authors retained the audio recordings to indicate that the correct protocol has been followed (Biedenbach \& Müller 2011). The confidentiality and autonomy of the participants in the selected study was observed. Permission was requested from the concerned ministry to perform the interviews. For all the interviews, the location and times were negotiated with the chosen participants. The interviews were conducted until data saturation was reached, with the aim of obtaining rich descriptive data that would enable an understanding of the participants' construction of knowledge and reality about strategic management practices (Nieuwenhuis 2016). Openended qualitative responses were analysed thematically through data reduction and conclusion creation, as well as triangulation to identify trends.

\section{Findings and inferences}

The research found that management assumes that the available systems to promote the execution of the strategic plan are not clearly outlined as there is a disjoint between planning and execution. It also emerged that the mechanisms for performance evaluation are not effective because no action is taken against ministries and departments that do not reach their commitments on agreed time milestones (quarterly, biannually or annually). Furthermore, there appears to be a dual reporting structure in the operations system, as the strategy implementers can be answerable to two line managers. This position came out as one of the participants had the following to say:

'We are indeed involved in the planning process, but our challenge is there are no punitive actions taken against underperformers and those departments who fall short of agreed targets. This means our evaluations are just ceremonial instead of doing it for corrections towards practical improvements. Sometimes those responsible for strategy execution are impeded by the dual or multiple reporting structure, which in turn confuses the system as reporting is meaningful when done to those who would have assigned the task in the first place' (Participant 3, Director, gender undisclosed)

Consequently, during a performance cycle, dual reporting line relationships or reporting relationships in a matrix may obstruct effective strategy execution. The majority of research participants concurred that despite the fact that the policy clearly states the roles and duties of managers and staff members in the performance management process, disagreements, goal misalignments, role conflicts and miscommunication can occur during the cycle, causing these matrix linkages to be derailed. After creating objectives, most people forget about them and only revisit them at the halfway assessments/evaluations. This might easily lead to misalignments in a matrix structure, resulting in conflict and frustration as things drift and shift. The study also reveals that in the planning process, the management is indeed guided by the organisational vision, but the actual operations are characterised by episodes of budget constraints as confirmed by the following quote:

'We plan but this is often influenced by budget restrictions as set targets are crippled by unavailability of funds in some cases and political intervention. For example, exchequer and cost centre virements are effected towards politically priority assignments which would not have been initially budgeted for, at the expense of priorly budgeted operating lines.' (Participant 5, Director, gender undisclosed)

Thus, the top-down approach to problem-solving structures make top layers (decision makers) override bottom layers (implementers) of the bureaucracy in policy implementation. Hence, random orders from top layers often supersede priorly agreed plans. Senior managers take the view that during the execution of the strategic plan, the performance management framework is not included in the design of the strategic plan and in addressing challenges. It was clear that quarterly performance reviews are used as a mechanism to promote the strategic plan's implementation. The findings indicate that although there is a system in place to promote the implementation of the strategic plan, the system is not well coordinated, particularly during the phase of formulation in the strategic planning process. Hence, the system tends to focus more on the implementation of the strategic plan when compared to effective for strategy formulation. In most cases, only deputy directors or above are invited to the ministerial departments' strategic planning processes.

It has also been found that the mechanism followed by the public sector or ministerial departments in facilitating the proper implementation of the strategic plan may not have harmonised standard operating procedures. The research found that, in terms of strategic planning systems or processes, there are diverse opinions as some officials claim that the ministry has no inclusive approach to planning in which all officials and/or stakeholders are involved and afforded the opportunity to engage in the process, yet others confirmed the presence of allencompassing annual planning workshops. It also emerged that there is a lack of understanding between the officials involved in the medium-term strategic structure processes, hence in terms of key performance areas and strategic management, the departments of the ministry are lacking.

The study results indicate that most of the public sector management attempts to strategically manage, align policies with the plan, fully engage workers in the execution of the strategy, continuously remind employees about strategic corporate governance, tracking strategy and execution to adapt it to suit the challenges and realities of the time. Furthermore, the study found that the failure of people to convert the plan to a corporate goal is the main challenge with strategic management. Based on the results, the authors suggest that strategic management decisions and the political landscape be addressed when managing public sector in order to build a successful strategic plan that will have a positive impact on institutional efficiency. The long-term strategies of public sector are therefore driven mainly by political considerations whilst 
short- to mid-term strategies are dominated by the operations and coordination activities. This trend is however situational, although in the case of Zimbabwean public service the strategic triangle was able to record the development of value by expanding three corners of the strategic triangle in daily management aligned to rational incrementalism.

Generally, strategic management was found to be more beneficial when organisations apply approaches to strategic management that matches the situation they are in. According to the study's findings, strategic management provides the following benefits. It brings about clearer definition of objectives, provides better guidance to the entire organisation, makes managers and organisational members more alert to new opportunities and issues threatening development, and helps in overcoming risks and uncertainties and therefore contributes to organisational success. This ultimately leads to improved value addition in the services given to the public. The study further found that strategy increases the quality of business decisions; it creates a more proactive management posture, helps to unify the organisation and promotes the development of a constantly evolving business model that will produce sustainability and fair service delivery for the public sector. Using the strategic management approach, where managers at all levels of a business interact in planning and implementation, has great behavioural consequences almost similar to those of participative decision-making.

Finally, the research found that a strategic triangle can be used as a viable tool for value creation.

Political variables dominate the strategy debate for long-term strategies. The mid- and short-term time horizons are dominated by collaboration and operations, although this trend can differ from case to case. Nonetheless, evidence indicates that by extending the three corners of the triangle through tactical measures in line with rational incrementalism, the strategic triangle may generate value. The overarching vision and themes centred on the creation of value can be achieved by a well-coordinated upward management (political), downward management (operations oriented) and outside management (coordination with various stakeholders) for mutualism symbiosis between the public and private sectors, as illustrated in Figure 2.

In relation to the present case study, the strategic triangle illustrates how public value is created when a strategy or action has democratic legitimacy such as community support, the support of the authorising environment such as a governing board and the government has the operational capacity to effectively implement the strategy or action. The study participants also demonstrated that there is a feedback mechanism in place because when public value is created, it is accompanied by improved legitimacy and support as society and elected officials have better trust in the government, as well as increased operational capacity. When managers strengthen the legitimacy and support perspective, it becomes simpler to acquire inputs such as money, volunteers and other resources

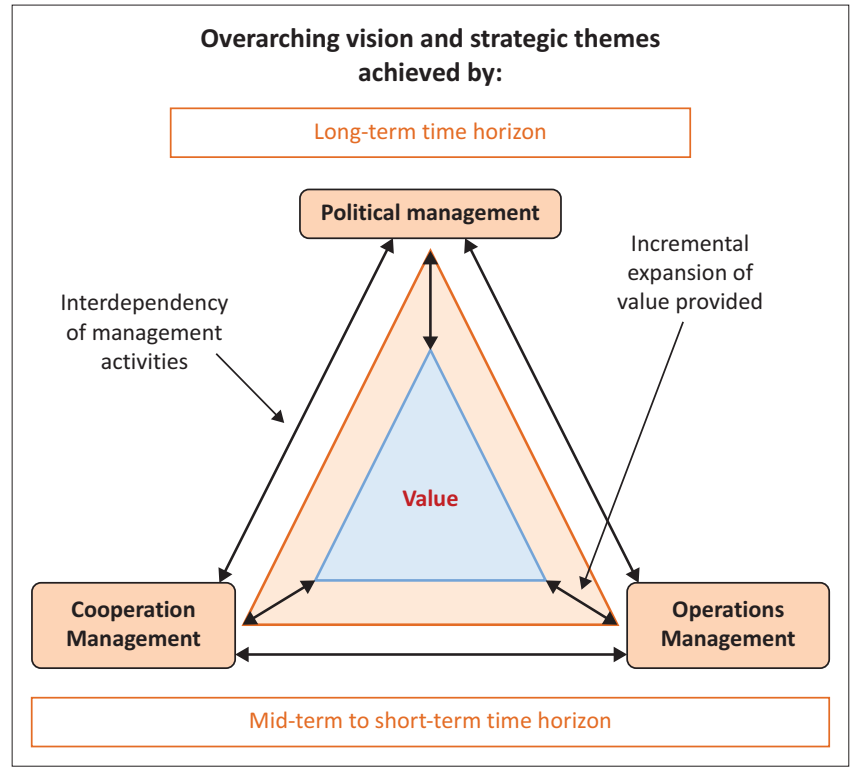

Source: McBain, L. \& Smith, J., 2010, 'Strategic management in the public sector', E-Leader Singapore 2010, 1-11

FIGURE 2: Value creation by using the strategic triangle.

into government organisations. When they strengthen their operational capabilities, those inputs are more efficiently and effectively transformed into public-value-generating outputs, resulting in increased legitimacy and support.

The key to strategic success is the establishment of strong partnerships internally and externally. The challenge of constantly developing and adjusting the strategy and means of attaining it seems to be more within the purview of the public sector manager because the political level might not be able to provide guidance on value creation. In order to shape broad support, the strategy itself together with a modern understanding of strategic management must be conveyed through the organisation in a manner that ensures ownership, so that strategy and adaptation are owned by all levels, usually because adaptation can take place at a tactical level. In view of the increasing complexity and the versatility of public service organisations, the multistep, goal-oriented approach to strategic management appears to be insufficient.

Logical incrementalism offers the best fit to complement given that real public circumstances are ambiguous, uncertain, and can easily change. The strategic triangle offers more marginal flexibility, decreases uncertainty, generates more focus, and is easily understandable.

\section{Conclusion}

This article, using the strategic triangle as a foundation, attempts to explain what types of management control practices allow and/or constrain public value. In this way, it complements previous research on public value, the increasing interest in the strategic triangle as an analytical framework for analysing empirical data and the demand for more empirical studies on the subject. Moore's (1995) strategic triangle can be a good tool for public managers to use in order to create 
possibilities that go beyond policy implementation and into value production for citizens. Public value management emphasises public sector innovation and the value of public sector managers. It is best thought of as a technique for public managers to notice and implement operational changes in their organisations. However, because of its elusiveness, determining public value remains a challenge. The concept 'value' is problematic in and of itself because it is subjective. This is because of the fact that the individual citizen's value position changes throughout time. Political dynamics, government policies and political leadership are all part of the strategic triangle and more study is needed in these areas. The rapidly changing environments necessitate a proactive management approach from top management in public organisations. The importance of strategic management is stressed by shifts in the political, economic, technical and social environments, as well as the need for improved efficiency. Applying successful strategic management gives organisations the opportunity to build on their internal resources as they grow and, as they arise, also leverage external opportunities. It can be concluded that strategic management has substantial positive effect on organisational success as it promotes the organisation to guard against threats and mitigate vulnerabilities before they become disruptive.

\section{Managerial implications}

The implication of the findings of the study is that strategic planning and decision-making has an important role in organisational development and sustainability. Various types of strategies used in strategic management by organisations require top-level executive managers to map for long-term organisational sustainability and to face or deviate from the competition. Consistency and a levelled eye on all relevant stakeholder inclusiveness are important in the translation of a strategy into a corporate purpose.

Strategy making has traditionally utilised strategic management, underpinned by rational strategic planning, to craft and implement strategic moves. However, rapidly changing environmental dynamics have created an operational environment contrary to the traditional paradigm of predictability, linearity and controllability expected by the rational strategic planning approach to strategy making.

Strategy is usually linked with the external environment in which the firm operates. Whether formulated with specific environmental threats and opportunities in mind or emerging incrementally from within the organisation much of what becomes or is interpreted as strategy has evolved with at least some sensitivity towards the external world (Ferlie \& Ongaro 2015).

In the strategic management, many contingency factors have been suggested to influence strategy.

Numerous summaries of the contingency literature have concluded that the external environment exerts a strong influence on strategy formulation or on the relationship between strategy and other variables such as performance (Gaddis 2018). Strategies connect goals and the capabilities required to accomplish them. Therefore, strategising requires the deliberate and evolving alignment of goals and capabilities, thus ensuring that goals can be accomplished or altered by taking into account existing capabilities and the potential need for new ones to be created. Strategic planning and management are unique methods that can help public sector institutions to effectively implement strategies. Each methodology consists of a collection of principles, procedures, processes, instruments, techniques and methods to be selectively used and adapted to particular contexts, even as the context itself is likely to change (Bryson \& George 2020).

Ignoring these factors in the traditional strategic management practices can derail the strategy execution of any organisation, regardless of whether the organisation operates in the private or the public domain. With this study drawing from experiences in the corporate sector for improvement of the organisational efficiency in the public sector, the findings indicate that the need for strategic management in the corporate sector is equally the same as in the public sector, if not actually greater in the public sector spheres. However, the increased instability and turbulence in the present global, political and economic environment requires leaders and managers to operate in a tactical context because it seems that strategic management from now on will operate in a chaotic environment. Therefore, change management would be the order of the day.

Strategic planning and management are approaches to identifying and addressing challenges. It is noteworthy that not a single invariant activity, but a set of values, processes, procedures, tools, techniques and practices must be selectively and strategically adapted to unique situations in order to produce desirable results. Whilst there are a range of generic approaches, the boundaries between strategic planning and management are not necessarily obvious, but the two are usually a hybrid (Bryson, Edwards \& Van Slyke 2018).

\section{Recommendations}

Based on the findings of the study, the authors recommend the following.

At the start of the planning process, the ministry should hold workshops on the medium-term strategic structure and the strategic plan every financial year. The relationship or connection between the medium-term strategic framework and the strategic plan, the correlation between the priorities of the medium-term strategic structure and the strategic plan, the intention of aligning the medium-term strategic structure with the strategic plan, and its role in the strategic planning phase should be clearly expressed during the workshops in order to ensure common understanding and agreement amongst all officials.

Departments should ensure that there is a connection between the strategic plan and its implementation. To promote the proper development and execution of the 
strategic plan, the ministry and its departments need to establish standard operating procedures or guidelines for the process. It is necessary for the departments under the ministry to review the effects of the previous strategic plan in order to include the objectives that were not attained when the strategic plan for the coming year is being formulated.

A Planning and Reporting Committee, chaired by the Permanent Secretary (Chief Operating Officer) and consisting of all heads of departments, should be formed by the ministry concerned and the respective departments. The committee will have the task of verifying quality assurance and authorising the strategic plan, the annual performance plan and the operating plans. The ministry needs to put stringent mechanisms to ensure that departments report on what has been scheduled and do not deviate from reporting on what is in the strategic plan or annual performance plan and take action against those who do not follow what is stated in the approved strategic and annual performance plan. Departmental heads (managers) are expected to report to the Planning and Monitoring Committee on their respective main performance areas, and departmental or sectional reports should be accepted by the committee prior to submission to the Permanent Secretary for approval and submission to the National Treasury.

Consolidating the findings from the research study, a strategic thinking approach framework is proposed. Each component of the framework uses its inventive and proactive nature to enable a revised worldview of internal and external threats and opportunities by encouraging entrepreneurial and creative synthesis. This will enable organisations to create new perspectives and unique combinations; define achievable strategic intent and generate future value for organisational stakeholders to ensure success, through competitive advantage, in a radically changing, uncertain and complex operational environment.

\section{Acknowledgements Competing interests}

The authors declare that they have no financial or personal relationships that may have inappropriately influenced them in writing this article.

\section{Authors' contributions}

N.C. contributed to the design and implementation of the research, to the analysis of the results and to the writing of the manuscript. W.F. and H.W. supervised, edited and funded the research.

\section{Ethical considerations}

This article followed all ethical standards for research, with ethical approval obtained from the Humanities and Social Sciences Research Ethics Committee at the University of KwaZulu-Natal, with project number HSS/1228/017D.

\section{Funding information}

This research received no specific grant from any funding agency in the public, commercial, or not-for-profit sectors.

\section{Data availability}

The data that support the findings of this study are available from the corresponding author, N.C., upon reasonable request.

\section{Disclaimer}

The views expressed in the submitted article are those of the authors and not an official position of the institution or funder.

\section{References}

Ahmadi, S.A.A., Salamzadeh, Y., Daraei, M. \& Akbari, J., 2012, 'Relationship between organisational culture and strategy implementation: Typologies and dimensions', Global Business and Management Research 4(3/4), 286

Altland, A. \& Simons, B.D., 2010, Condensed matter field theory, Cambridge University Press, Cambridge.

Biedenbach, T. \& Müller, R., 2011, 'Paradigms in project management research: Examples from 15 years of IRNOP conferences', International Journal of Managing Projects in Business 4(1), 82-104. https://doi.org/10.1108/17538371111096908

Briones, C.T.L., 2020, 'Una nueva estimación del índice del costo de la vida, Argentina 1912-1932', Boletín Del Instituto De Historia Argentina Y Americana Dr. Emilio Ravignani 53(2), 64-92. https://doi.org/10.34096/bol.rav.n53.8006

Briones, C.T.L. \& González Bollo, H., 2017, 'Unwinding the winding trajectory: The divergence between national accounts and state planning, Argentina 1937-1948', Histoire \& Mesure 32(1), 161-190.

Bryson, J. \& George, B., 2020, Strategic planning for public and nonprofit Organizations: A guide to strengthening and sustaining organizational achievement, Jossey-Bass Inc., San Francisco, CA.

Bryson, J.M. \& Edwards, L.H., 2017, 'Strategic planning in the public sector', in R. Aldag (ed.), Oxford research encyclopedia of business and management, Oxford University Press, Oxford.

Bryson, J.M., Edwards, L.H. \& Van Slyke, D., 2018, ‘Getting strategic about strategic planning research', Public Management Review 20(3), 317-339. https://doi.org/1 0.1080/14719037.2017.1285111

Bryson, J.M. \& Schively Slotterback, C., 2017, 'Strategic spatial planning in the USA', in L. Albrechts, A. Balducci \& J. Hillier (eds.), Situated practices of strategic planning, Routledge, New York, NY.

Da Silva, S.S., Spers, R.G., Oliveira, M.A. \& Fischmann, A.A., 2019, 'The strategic management practice in an online experiential learning laboratory', Revista IberoAmericana de Estratégia 18(3), 382-396. https://doi.org/10.5585/ijsm.v18i3.2754

David, F.R., 2013, Strategic management: Concepts and cases, Pearson Education Ltd., Essex.

Daymon, C. \& Holloway, I., 2010, Qualitative research methods in public relations and marketing communications, Routledge, New York, NY.

Emerson, K. \& Nabatchi, T., 2015, Collaborative management regimes, Georgetown University Press, Washington, DC.

Engida, T.G. \& Bardill, J., 2013, 'Reforms of the public sector in the light of the new public management: A cases of sub-Saharan Africa', Journal of Public Administration and Policy Research 5(1), 1-7. https://doi.org/10.5897/JPAPR11.019

Ferlie, E. \& Ongaro, E., 2015, Strategic management in public sector organisations: Concepts, schools, and contemporary issues, Routledge, New York, NY.

Gaddis, J.L., 2018, On grand strategy, Penguin, New York, NY.

George, B., Desmidt, S., Cools, E. \& Prinzie, A., 2018, 'Cognitive styles, user acceptance and commitment to strategic plans in public organisations: An empirical analysis', Public Management Review 20(3), 340-359. https://doi.org/10.1080/14719037.2 017.1285112

Hendry, E., Hale, P.J., Moger, J., Savchenko, A.K. \& Mikhailov, S.A., 2010, 'Coherent nonlinear optical response of graphene', Physical Review Letters 105(9), 097401. https://doi.org/10.1103/PhysRevLett.105.097401

Hope, Sr, K.R., 2005, 'The new public management: Context and practice in Africa', International Public Management Journal 4(2), 119-134. https://doi.org/10.1016/ S1096-7494(01)00053-8

Immers, B. \& Duijn, M., 2005, The use and value of hierarchical governance and modelling in infrastructure network planning, Oxford University Press, New York, NY.

Joyce, P., 2015, Strategic management in the public sector, Routledge, New York, NY.

Kania, J. \& Kramer, M., 2011, 'Collective impact', Stanford Social Innovation Review $6(1), 36-41$. 
Kenis, P. \& Provan, K.G., 2009, 'Towards an exogenous theory of public network performance', Public Administration 87(3), 440-456.

Maas, H. \& Svorenčík, A., 2017, "“Fraught with controversy": Organising expertise against contingent valuation', History of Political Economy 49(2), 315-345. https:// doi.org/10.1215/00182702-3876493

Maleka, S., 2014, 'Strategy management and strategic planning process', DTPS Strategic Planning \& Monitoring 1, 1-29.

McBain, L. \& Smith, J., 2010, 'Strategic management in the public sector', E-Leader Singapore 2010, 1-11.

Moore, M.H., 1995, Creating public value: Strategic management in government, Harvard University Press, Cambridge.

Nieuwenhuis, J., 2016, 'Introducing qualitative research', in K. Maree (ed.), First steps in research, 2nd edn., Chapter 4, pp. 50-69, Van Schaik, Pretoria.

Pemberton, J. \& Stonehouse, G., 2004, 'The organisational characteristics of knowledgecentricity', in B. Montano (ed.), Innovations of knowledge management, pp. 99-123, IRM Press, London.

Poister, T.H., 2010, 'The future of strategic planning in the public sector: Linkin strategic management and performance', Public Administration Review 70(Suppl. 1), s246-s254.
Poister, T.H., Edwards, L.H. \& Pasha, O., 2013, 'The impact of strategic planning on organisational outcomes', Public Performance and Management Review 36(4), 585-615. https://doi.org/10.2753/PMR1530-9576360405

Pollitt, C. \& Bouckaert, G., 2017, Public management reform: A comparative analysisinto the age of austerity, Oxford University Press, Oxford.

Raab, J., Mannak, R.S. \& Cambré, B., 2015, 'Combining structure, governance and context: A configurational approach to network effectiveness', Journal of Public Administration Research and Theory 25(2), 479-511. https://doi.org/10.1093/ jopart/mut039

Sandfort, J. \& Moulton, S., 2015, Effective implementation in practice: Integrating public policy and management, Jossey-Bass, San Francisco, CA.

Talbot, C., 2010, Theories of performance: Organisational and service improvement in the public domain, Oxford University Press, New York, NY.

Thom, N. \& Ritz, A., 2008, Public management, Gabler, Wiesbaden.

Van Dooren, W., Bouckaert, G. \& Halligan, J., 2015, Performance management in the public sector, 2nd edn., Routledge, New York, NY.

Weick, K.E. \& Sutcliffe, K.M., 2015, Managing the unexpected: Sustained performance in a complex world, John Wiley \& Sons, Hoboken, NJ. 